\title{
Current or Recent Employee or Volunteer in Jail or Prison
}

National Cancer Institute

\section{Source}

National Cancer Institute. Current or Recent Employee or Volunteer in Jail or Prison. NCI

Thesaurus. Code C102614.

An individual who is presently or not long ago worked or offered to assist without pay at an institution where persons are confined for punishment and to protect the public. 